\title{
Ge-Zr (Germanium-Zirconium)
}

\section{H. Okamoto}

The Ge-Zr phase diagram in [Massalski2] was redrawn from [1986Abr]. The outline of the phase diagram was based on [1956Car]. The $\mathrm{Ge}_{4} \mathrm{Zr}_{5}$ phase, which was found first by [1965Ros], was added to this phase diagram. Because the formation reaction of $\mathrm{Ge}_{4} \mathrm{Zr}_{5}$ was unknown, [1986Abr] showed this phase only up to $1620^{\circ} \mathrm{C}$. The liquidus of $\mathrm{Ge}_{3} \mathrm{Zr}_{5}$ in [1956Car] was very asymmetric around the congruent melting point. This unlikely feature was transcribed in [1986Abr].

Figure 1 shows the Ge-Zr phase diagram calculated by [2011Sha] based on literature data and their own measurements. The problem of asymmetry described above has been solved.

\section{References}

1956Car: O.N. Carlson, P.E. Armstrong, and H.A. Wilhelm, Zirconium-Germanium Alloy System, Trans. ASM , 1956, 48, p 843-854

1965Ros: W. Rossteutscher and K. Schubert, Structure Investigation in Some $\mathrm{T}^{4 \ldots 5}-\mathrm{B}^{4 \ldots 5}$ Systems, Z. Metallkd., 1965, 56, p 813-822, in German

1986Abr: J.P. Abriata, J.C. Bolcich, and D. Arias, The Ge-Zr (Germanium-Zirconium) System, Bull. Alloy Phase Diagr., 1986, 7(1), p 43-47

2011Sha: C. Sha, L. Zhou, S. Liu, Y. Du, T. Gang, and H. Xu, Phase Equilibria and Thermodynamic Modeling in the Ge-Zr Binary System, J. Mater. Sci., 2011, 46(5), p 1405-1413

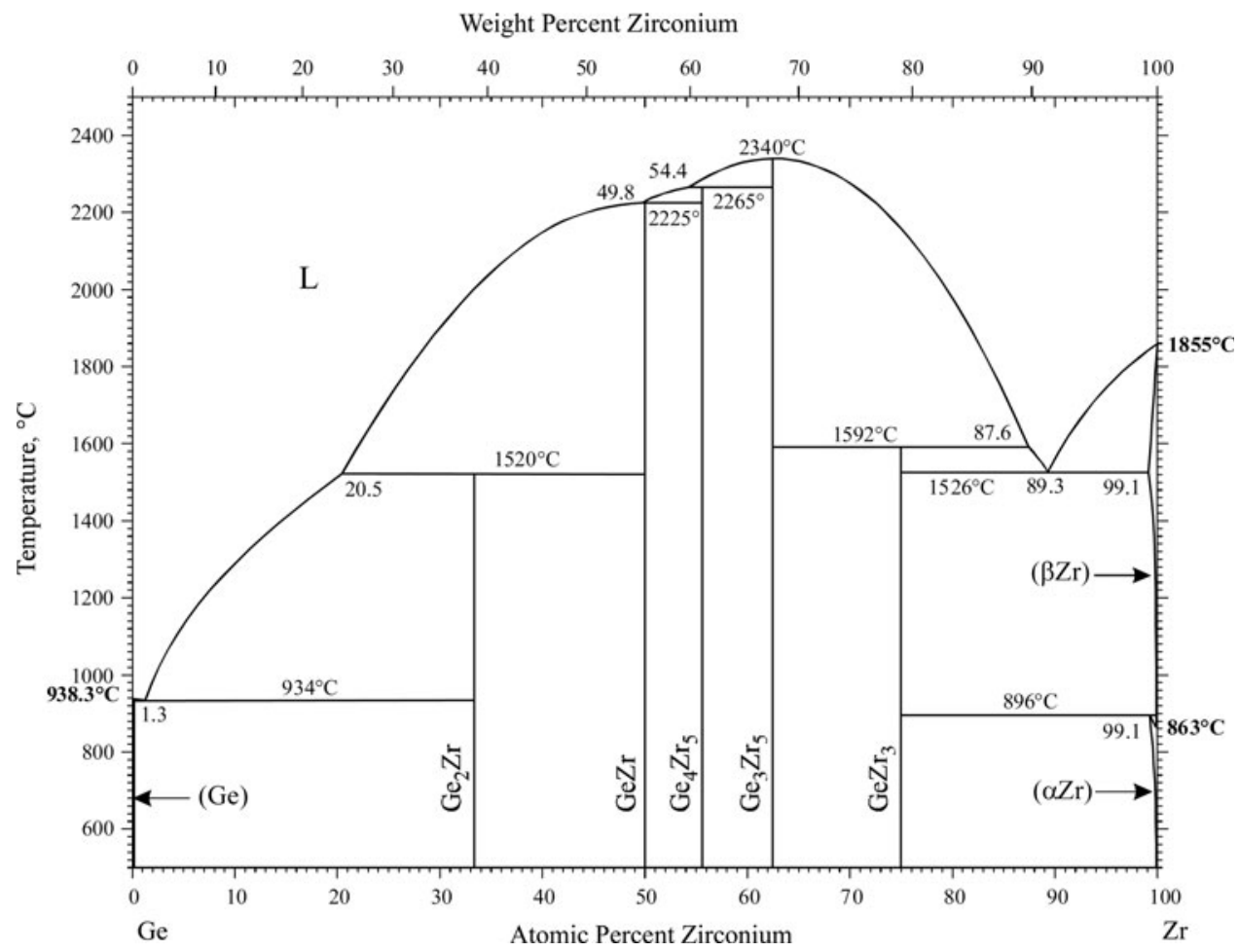

Fig. 1 Ge-Zr phase diagram 